\title{
Coordination of iron in E-glass
}

\author{
B. E. RAMACHANDRAN, N. BALASUBRAMANIAN' \\ Material Sciences Division, National Aeronautical Laboratory, Bangalore 560 017, India
}

Iron is usually present in glasses either as an impurity from the raw materials used or as an additive. Its presence confers on the glass a number of properties, notably colour [1] and magnetism [2-4]. E-glass, which has $0.3 \% \mathrm{Fe}_{2} \mathrm{O}_{3}$, was in rod form a pale green colour which is due to iron ions. Iron is used alone or in combination in the commercial production of green-coloured glass. Most of the oxides of the first series of transition metals produce a strong colour when present in an oxide glass at a concentration of less than 1 Yo. These transition metal ions are incorporated in the glass structure each being surrounded by oxygen anions and are also responsible for the paramagnetism in glasses. This letter reports on the coordination of iron in E-glass. It was of interest to use magnetic measurements to detect iron because the objective was to eliminate $\mathrm{Fe}_{2} \mathrm{O}_{3}$ (and all other oxides) to obtain high-purity silica. The starting material was E-glass of the composition, $54.2 \mathrm{wt} \% \mathrm{SiO}_{2}, 14.0 \mathrm{wt} \% \mathrm{Al}_{2} \mathrm{O}_{3}$, 19.8 wt $Y_{0} \mathrm{CaO}, 2.2 \mathrm{wt} \% \mathrm{MgO}, 8.2 \mathrm{wt} \% \mathrm{~B}_{2} \mathrm{O}_{3}$, $0.3 \mathrm{wt} \% \mathrm{Fe}_{2} \mathrm{O}_{3}$ and 0.56 wt $\boldsymbol{Y}_{\mathrm{o}} \mathrm{Na}_{2} \mathrm{O}+\mathrm{K}_{2} \mathrm{O}$. This was leached in HCI in order to obtain $98 \%$ silica. A complete description of the process as well as the changes in physical properties as a result of leaching have been given previously [5-10].

The magnetism in E-glass is due entirely to the presence of iron as there are no other transition metal ions. In the present study, fine powdered samples of E-glass were used to measure the magnetic susceptibility using the standard Gouy method. It was found to be $0.6017 \times 10^{-6} / \mathrm{g}$ ion. From this value the magnetic moment can be calculated to be 5.8 Bohr magnetons. It is known [4] that a value of 5.90 Bohr magnetons indicates that the iron atom is the ferric state.

It was found that the gram suceptibility decreased with leaching time. The glass sample when leached in $4 \mathrm{~N} \mathrm{HCl}$ for different periods of time at $100^{\circ} \mathrm{C}$ loses the paramagnetism and becomes diamagnetic. The values were found to be $0.1217 \times 10^{-6} / \mathrm{g}$ ion at $0.5 \mathrm{~h}$ and $0.0236 \times 10^{-6} / \mathrm{g}$ ion at $1 \mathrm{~h}$. After $2 \mathrm{~h}$ of leaching, the material became diamagnetic. The decrease in gram susceptibility is due to the removal of paramagnetic centres, namely $\mathrm{Fe}^{3+}$ ions, by hydrochloric acid. The paramagnetism introduced into a glass by the incorporation of iron ions, arises from the unpaired electrons of the unfilled $3 \mathrm{~d}$ subshell of this element. The contribution of electrons to magnetic properties is strongly influenced by the surrounding electrostatic fields [11].

Iron can be in fourfold or sixfold coordination $[12,13]$ which can be confirmed by Mossbauer [14] or ESR spectroscopy. We used the latter method at a

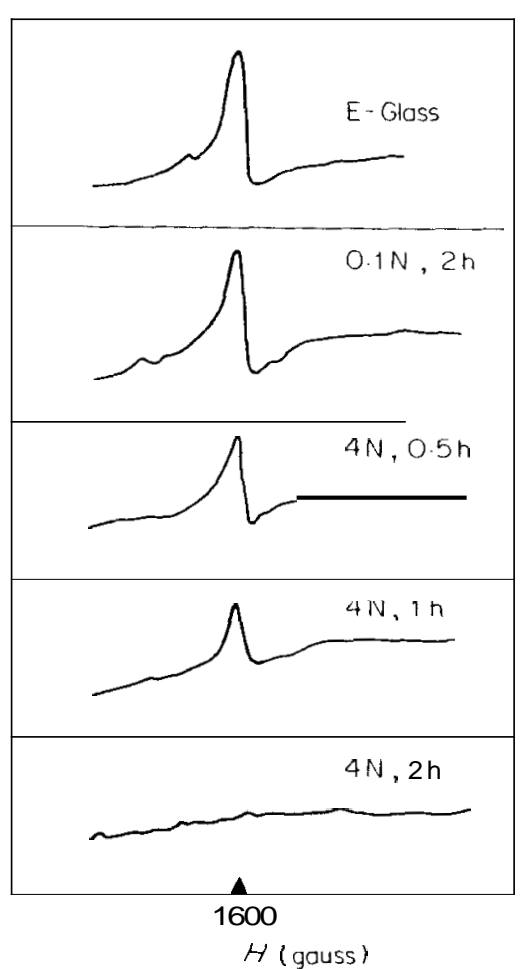

Figure I ESR spectra of $\mathbf{E}$ glass and leached $\mathbf{E}$ glass.

frequency of $9.49 \mathrm{GHz}$. Initially the field was set at $3250 \mathrm{G}$ and the scan range was $2000 \mathrm{G}$ (i.e. 2250 to $4250 \mathrm{G}$ ). To the powdered sample of E-glass, reference material diphenyl dipicryl hydrazine (DPPH) was also added. But for the DPPH peak, no other peak was observed. If iron were present in sixfold coordination a peak would have appeared at $3250 \mathrm{G}$. The field range was then increased to $4000 \mathbf{G}$ and the field was set at $2200 \mathrm{G}$ (i.e. 200 to $4200 \mathrm{G}$ ). A single peak was observed, as shown in Fig. 1, at $1600 \mathrm{G}$ indicating that the only species present is iron with a four-fold coordination. Previous work has shown that in sodium silicate glass, $\boldsymbol{g}=2$ resonance indicates that the $\mathrm{Fe}^{3+}$ is in six-fold coordination (or as a network modifier) and that $g=4.28$ resonance shows that $\mathrm{Fe}^{3+}$ ion is in four-fold coordination (or as a network former) $[15,16]$. The $g$ value of 4.28 corresponds to the field $(\boldsymbol{H})$ value of $1600 \mathrm{G}$ and $g=2$ corresponds to $H$ of $3250 \mathrm{G}$. The observed peak thus indicates the presence of $\mathrm{Fe}^{3+}$ in four-fold coordination. Fig. 1 shows the ESR spectra of E-glass in three conditions (i) unleached, (ii) leached in $4 \mathrm{~N} \mathrm{HCl}$ for various times and (iii) leached in $0.1 \mathrm{~N} \mathrm{HCI}$ for $2 \mathrm{~h}$. Both in untreated and mildly treated E-glass the $1600 \mathrm{G}$ peak is present, the peak height decreasing with leaching 
time. But with severe treatment the peak disappears completely.

The conclusions are (a) the ESR measurements show that $\mathrm{Fe}^{3+}$ ion is present in E-glass in four-fold coordination and has the role of a netwo th former. (b) Iron oxide can be removed completely from the E-glass by leaching with $4 \mathrm{~N} \mathrm{HCI}$ for $2 \mathrm{~h}$ and the glass becomes diamagnetic as shown by both ESR and magnetic susceptibility measurements.

\section{References}

1. C. R. B A MFORD, "Colour Generation and Control in Glass" (Elsevier, New York, 1977).

2. G. W. MOREY, "The Properties of Glass" 2nd edn (Reinhold, New York, 1954).

3. H. COLE, J. Soc. Glass Technol. 34 (1950) 220.

4. C. R. B A M F O R D, Phys. Chem. Glasses 35 (1957) 25.

5. B. E. RAMACHANDRAN, B. C. PAI and N. BAL A S U E R A M A N I A N, J. Am. Ceram. Soc. 63 (1980) 1.

6. Idem, J. Mater. Sci. 14 (1979) 1572.

7. B. E. RAMACHANDRAN, B. C. PAI and N. BALASUBRAMANIAN, G. V. SUBHA RAO and G. ARA.
V A M U D A N, ihid. 16 (1981) 1611

8. B. E. RAMACIIANDRAN. N BALASUBRAMANIAN, G. V. SUBHA RAO and G. ARAVAMUDAN. Bull. Mater. Sci. 3 (1981) 333.

9. B E. RAMACHANDRAN. B C. PAI and N BAL ASUBR AMANIAN, Mater. Sci. Engng 43 (1980) 199.

10. B. E. RAMACHANDRAN and N BALASUBRAMANIAN, J. Mater. Sci. Lett. 4 (1985) 688.

11. H. R RAWSON, "Properties and Applications of Glass", Vol. 3 (Elsevier, New York, 1980).

12. C. H. Hiroyama, Phys. Chem. Glasses 9 (1968) 109

13. J. WONG and C A. ANGEL, "Glass Structure by Spectroscopy" (Marcel-Dekker, New York, 1976).

14. C. R. K U R K J I A N. J. Non Crysi. Solids3 (1970) 157.

15. R. F. TUCKER, "Advances in Glass Technology". VI International Congress on Glass (Plenum, New York, 1962) p. 103.

16. G. O. KARAPETYON, V. A. TSKHONSHI and D. M YUDIN, Sov. Phys. Solid State 5 (1963) 456

Received 3 April

and accepted 9 April 1986 